\title{
Dynamic modeling and control strategies analysis of a novel small CSP biomass plant for cogeneration applications in building
}

\author{
Adriano Desideri ${ }^{1}$, Simone Amicabile ${ }^{2}$, Fabrizio Alberti ${ }^{2}$, Silvio Vitali-Nari ${ }^{3}$, Sylvain Quoilin ${ }^{1}$, \\ Luigi Crema ${ }^{2}$, Vincent Lemort ${ }^{1}$ \\ ${ }^{1}$ University of Liège, Campus du Sart Tilman - Bat: B49 - P33 4000 Liège, Belgium \\ ${ }^{2}$ ARES Unit, Fondazione Bruno Kessler, 38123 Povo, Trento (Italy) \\ ${ }^{3}$ ACCIONA, Sevilla, Andalucia, Spain
}

\begin{abstract}
A concentrated solar power (CSP) biomass combined heat and power (CHP) system based on organic Rankine cycle (ORC) technology developed in the framework of the EU founded BRICKER project is presented. The CHP system coupled with heat recovery ventilation technology and novel insulation material has the aim of reducing the energy consumption of existing building by up to 50\%. A simplified approach to implement a dynamic model of the CHP system is proposed. The model is firstly used to investigate the performances of the CHP system control logic under extreme working condition. Secondly, the effectiveness in ensuring safe working conditions and in maximizing the sun power usage of two different solar field control approaches is investigated simulating the developed model over a reference day.
\end{abstract}

Keywords: Hybrid CSP, organic Rankine cycle system, Dynamic modeling

\section{Introduction}

Over the past 30 years the electric industry has been characterized by a transition from a vertical production structure towards an horizontal one based on the deployment of intermittent renewable resources (Hinkley et al., 2011). Among renewable energy technologies, concentrated solar power (CSP) systems have been increasingly considered worldwide as a key technology for meeting the renewable energy demand (Resnick Institute, 2012) (Mediavilla et al., 2013). Due to the high capital cost, the total CSP installed capacity is still low, with only $3.6 \mathrm{GW}_{\text {el }}$ installed at the end of 2013 (IEA, 2014) . Research activities, with a focus on cost reduction, have been commissioned by leading research institute in Europe and in the US (Pitz-Paal et al., 2007) (Hinkley et al., 2011), and significant reductions are expected especially for the thermal storage (TES) and the heat transfer fluid (HTF) components by the end of this decade. Another approach to achieve competitiveness in the current market consists in hybridization with fossil fuels (Peterseim et al., 2013). Hybridizing these plants has not only the benefit of reducing the cost but it also enables the CSP unit to be dispatchable when the solar source is low. Several plants worldwide have demonstrated the advantages of this solution (Agency, 2014). In recent years, the hybridization of CSP technology with biomass has gained attention and its potential has been investigated by several authors (Peterseim et al., 2014a) (Soria et al., 2015). The concept has been successfully demonstrated since the end of 2012 by the $22 \mathrm{MW}_{\mathrm{el}}$ Termosolar Borges plant in Catalonia, Spain (NREL, 2013). This solution allows to move CSP technology towards agricultural area, rich in biomass and waste material, enabling locations with lower levels of direct normal irradiance (DNI) compared to DNI required by CSP standalone systems (Peterseim et al., 2014b). A technical economic assessment of a combined heat and power (CHP) system, using organic Rankine cycle (ORC) technology integrated with an hybrid CSP-biomass heat source, has been recently investigated (Sterrer et al., 2014). The study compares, by means of a transient analysis, the economic profitability of a hybrid CSP system for three different locations in central Europe, concluding that the retrofit of biomass 
plants with CSP technology is a promising approach, to improve the economic performances. In this context the EU founded BRICKER project aims to develop a scalable, replicable, high energy efficient, zero emissions and cost effective CSP-Biomass trigeneration system, based on ORC technology, to refurbish existing public-owned non-residential buildings. The CHP unit together with lightweight facades, and phase change material insulation technology, is expected to reduce the building energy consumption by at least $50 \%$. Three systems are being developed in Spain, Belgium and Turkey to demonstrate the concept feasibility. In this contribution, a dynamic model of the CSP-biomass CHP system under development in Cacares, Spain is presented. The transient model, developed in the Modelica language (Mattson et al., 1997), is simulated under extreme conditions to investigate the capability of the control logic in ensuring safe working operation. During the last years dynamic modeling has been increasingly recognized as a powerful tool to analyze the performance of CSP power system under transient conditions. Casati et al. (2012) developed a dynamic model of a novel ORC power block for a CSP system with a direct thermal storage, in order to investigate the controllability aspect under extreme critical conditions. The performance of a micro CSP-ORC system, over four reference days, has been analyzed by means of a detailed dynamic model by (Ireland et al., 2014). More recently Dickes et al. (2015) investigated model reduction methods for dynamic modeling of the solar field and the thermal storage of a micro CSP power unit, in order to increase the computational effectiveness of the models. In the presented work, a simplified modeling approach of the CSP-Biomass-ORC system is proposed. The proposed modeling approach allows for a robust and efficient model still capable of predicting the main time constants characterizing the overall system. The simulation results are analyzed and discussed and guidelines for the future work are drawn.

\section{System description}

The EU founded BRICKER project aims at demonstrating that retrofitting existing buildings with passive and active cutting edge technologies can lead to enormous energy savings. The project comprises the installation of a novel CHP unit based on renewable energy sources to meet the thermal and electrical building demand, coupled with heat recovery ventilation system, lightweight facades and innovative insulation material to decrease the building energy consumption. In this work the control logic of the CHP system is presented and its effectiveness is investigated by means of dynamic modeling. The complete layout of the CHP system under development in Cacares, Spain is reported in figure 1. The system is composed by two main loops. In the first loop the thermal energy collected by the parabolic trough collectors (SF) and produced by biomass combustion in the boiler (BMB) is transferred by an heat transfer fluid (HTF) to the ORC power block for electricity production and to the second loop via an heat exchanger (HXI). The synthetic thermal oil, TherminolSP, is selected as heat transfer fluid as it is widely used for CSP applications thanks to its low operating pressure, high thermal stability (up to $335^{\circ} \mathrm{C}$ ) and good heat transfer characteristics (Alberti et al., 2012). Starting from the bottom left of figure 1 it is possible to recognize the solar field, where the HTF is pre-heated from (a) to (b) before entering the biomass system (d), reaching the maximum temperature at the outlet of the boiler (e). The fluid is then pumped through HXI from (f) to (g) and through the ORC power block which are connected in parallel. At the outlet of the ORC unit, the fluid mixes with the stream coming from HXI (h). 


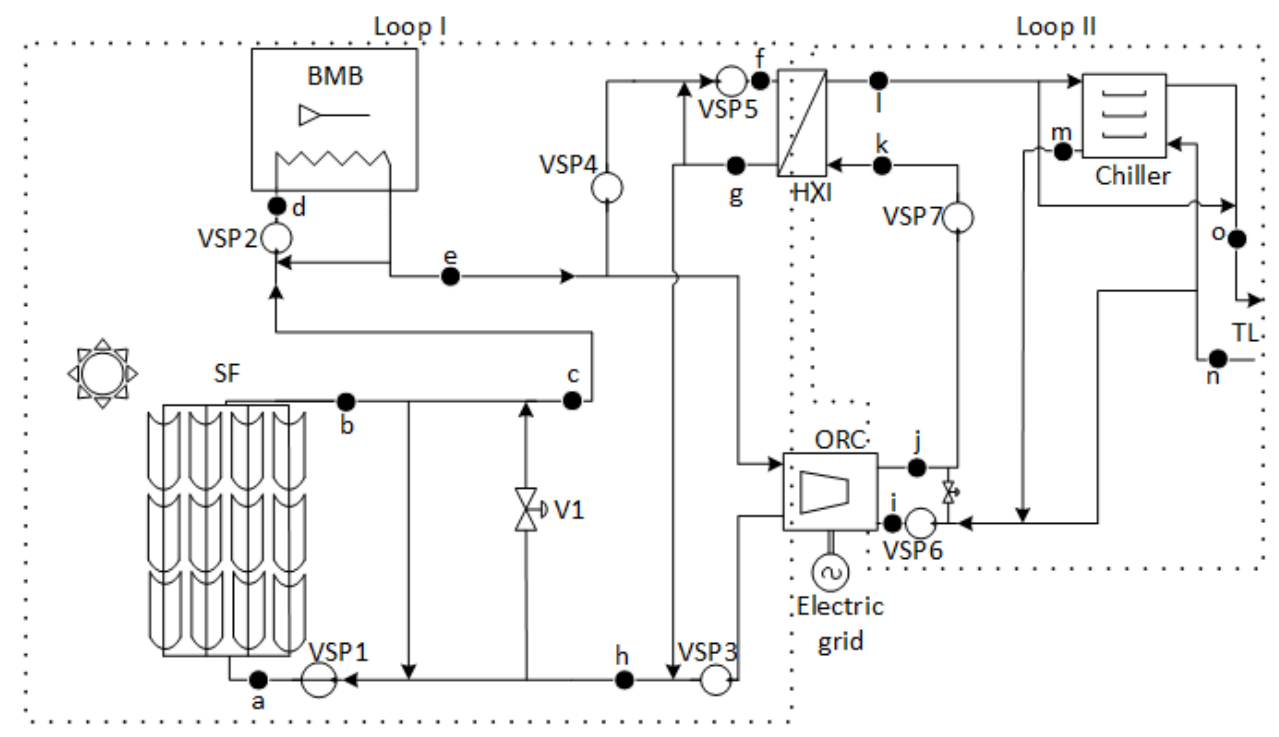

Fig. 1 Schematic flow diagram of the bricker CHP system.

Loop II comprises the adsorption chiller, the ORC condenser cooling side, the secondary side of HXI and the connection to the thermal load of the building. Looking at the right part of figure 1 the heat transfer fluid is first pre-heated in the ORC condenser from (i) to (j), and then it is pumped through HXI from (k) to (l) where it reaches the maximum temperature of loop II. The fluid is then directed to the Chiller or to the building depending on the thermal demand. A description of the different components is reported in the list below.

- Parabolic trough collectors with evacuated tubular absorber are selected being the most reliable and proven technology in the CSP field (Cabello et al., 2011). In particular the selected collectors are characterized by a maximum temperature of $250^{\circ} \mathrm{C}$ that perfectly fits the nominal working temperature of the system. A total of 12 collectors are connected in 4 parallel loop of 3 collector each. The solar field dimension results from a compromise between the available area on the demo building roof and on the seasonal thermal demand. The solar field works as a pre-heater for the biomass boiler, reducing the amount of biomass burnt during the day. Each solar collector is characterized by a net collecting surface of $54 \mathrm{~m}^{2}$.

- The biomass boiler covers a fundamental role in the system as it provides together with the solar field the thermal power required by the ORC unit and by HX1. If there is a sudden demand of extra power, a larger amount of biomass is burnt to keep the outlet temperature close to the set point value.

- The thermal energy from the biomass and the solar field is converted into electrical energy by the ORC power block. The ORC unit converts thermal energy into electrical energy based on the same principle of the steam Rankine cycle. The major difference with a traditional Rankine cycle is related to the employed working fluid which is an organic compound. The thermodynamic characteristics of the working fluid make the ORC technology a viable and interesting solution for low temperature power generation compared to a steam Rankine cycle. ORC systems have been proven to be a reliable mature and efficient technology over the years (Angelino et al., 1984) and their application to renewable energy sources for small scale power generation (5-200 $\left.k W_{e l}\right)$ is gaining popularity at a commercial level (Quoilin et al., 2013). The unit installed in the system can be operated in generation or cogeneration mode with an electrical power ranging between 100 and $70 k W_{e l}$ respectively. The electrical power can be sent to the building or the national grid. In cogeneration mode the thermal energy dissipated at the condenser is used by the cooling water for meeting the building thermal demand.

- An heat exchanger is used for thermal energy transfer between loop I and loop II. The brazed plate type is selected as it offers very good heat transfer performance in single phase with an extreme 
compact design (Palm and Claesson, 2006). In order to satisfy the cooling demand during the summer season an adsorption chiller machine is included in Loop II. The selected chiller is of the silica gel-water type. This machine can be fed with a thermal input ranging between $60-90^{\circ} \mathrm{C}$ (Wang and Vineyard, 2011).

\section{Control Strategy}

\subsection{Technical boundaries and operational logic}

In this section a description of the control logic implemented on the presented system is described and discussed. The technical boundaries of the different components are listed hereunder:

- Solar field: a minimum mass flow rate must be guaranteed in the parabolic through collectors to avoid high film temperature that could deteriorate the thermal oil. An autonomous warning control is provided by the manufacturer. When the outlet temperature of the solar field reaches a certain value, electrical motors are activated defocusing the collectors in order to decrease the temperature. A partial or total defocusing can be selected by the user.

- Biomass boiler: the boiler works in a range between 150 and $500 \mathrm{~kW}$ el with the former value representing the shutdown condition. The temperature gradient comprises between $5 \mathrm{~K}$ and $30 \mathrm{~K}$. The system operates at a constant mass flow of $9.5 \mathrm{~kg} / \mathrm{s}$ and is equipped with a recirculation circuit and an internal control which regulates the amount of biomass burnt to keep the temperature at the outlet at a user-defined set point. Power modulation is characterized by time constant between 30 seconds up to 2 minutes. This is mainly related to the kinetics limit of the combustion chemical process and to the air inflow adjustment. A limit of 1 daily start/stop is recommended by the manufacturer but it is preferably to maintain the biomass boiler at a minimum range in order to keep high efficiency, low pollutions and reduced maintenance. The boiler start-up is a slow process that can take up to 50 minute.

- $\quad$ ORC unit: it requires at the evaporator a constant thermal oil mass flow rate of $2.5 \mathrm{~kg} / \mathrm{s}$ and it is capable of handling heat source temperature deviation in the order of $20 \mathrm{~K}$ from the nominal value of $245^{\circ} \mathrm{C}$.

- Adsorption chiller: it can handle temperature inlet variation in the order of plus minus $5 \mathrm{~K}$ from its nominal value. Proper control of HXI are required in order to respect these boundary limits.

Given the above mentioned technical boundaries, a correct operation of the system depends on finding the right balance between the solar field and the biomass boiler working condition. In particular, high controllability of the solar field is required in order to guarantee safe biomass boiler operation avoiding biomass shut-down. In order to achieve this goal the solar field is equipped with a recirculation and a bypass stream as shown in figure 1. A constant mass flow rate equal to the nominal value required by the ORC evaporator of $2.5 \mathrm{~kg} / \mathrm{s}$ is ensured to the solar field by running pump VSP1 at a fixed speed, avoiding high film temperature issues. A highly responsive control logic is developed by installing a PI controller (PI1) on the by-pass valve V1 to regulate the biomass inlet temperature $T_{d}$ and by exploiting the solar field internal defocusing mechanism. In nominal condition the mass flow at the outlet of the ORC unit is pre-heated in the solar field and the by-pass valve V1 is closed. If the DNI overcome its nominal value the solar field outlet temperature $T_{b}$ increases and so does the biomass boiler inlet temperature $T_{d}$. The by-pass valve is opened by the PI controller to mitigate the temperature increase at biomass inlet $\mathrm{T}_{\mathrm{d}}$. As VSP1 runs at constant speed, mass flow rate equal to the one flowing through V1 is recirculated from SF outlet to the inlet, further increasing the solar field outlet temperature $T_{b}$. A chain mechanism is activated pushing $T_{b}$ towards the defocusing set-point value. When $\mathrm{T}_{\mathrm{b}}$ overpasses the set-point, automatic defocusing occurs, reducing the thermal power delivered by the collector fields and avoiding biomass shut down. On the other hand, sudden decrease of sun power are handled by the biomass internal control (PI2) which increases the biomass fed to the combustion chamber maintaining $\mathrm{T}_{\mathrm{e}}$ at its nominal value. In case the heat rejected from the ORC's condenser is not sufficient to satisfy the thermal demand of the building, extra power has to be delivered to the water loop of the system via HXI. The heat exchange rate of HXI is controlled by a recirculation system 
with pump VSP4 and VSP5. The latter is kept constant at a fixed speed. As the adsorption chiller works at a constant inlet temperature, $\mathrm{T}_{1}$, to guarantee high COP values, an increase in thermal demand corresponds to an increase in mass flow through HXI. A PI (PI3) controlling the rotational speed of VSP4 is implemented to maintain the temperature, $\mathrm{T}_{1}$, close to its set-point. In table 1 the controlled and control variables of the three PI characterizing the plant logic are summarized.

Tab 1. : Table summarazing the controlled and control variables of the three PI contrellers of the implemented control logic.

\begin{tabular}{|c|c|c|}
\hline Controller & Controlled variables & Control variables \\
\hline PI1 & Valve V1 aperture & $\mathrm{T}_{\mathrm{d}}$ \\
\hline PI2 & Amount of biomass burnt & $\mathrm{T}_{\mathrm{e}}$ \\
\hline PI3 & $\begin{array}{c}\text { Pump VSP4 rotational } \\
\text { speed }\end{array}$ & $\mathrm{T}_{1}$ \\
\hline
\end{tabular}

\section{Dynamic Modeling}

The proposed control strategy presented in section 3 is investigated under transient conditions by means of a dynamic model of the plant. The model is developed using the Modelica object-oriented modeling language (Elmqvist and Mattsson, 1997), and are based on the ThermoCycle library (Quoilin et al., 2014). The thermal oil flowing through loop I of the plant is always in liquid state and it is assumed to behave as an incompressible fluid. It is modeled following the table based approach proposed by the Modelica standard library. Temperature, $T$, is selected as the fluid model state variable. Density, $\rho$, and specific heat capacity, $c_{p}$, are computed fitting constant n-order polynomials on user-defined table data. Specific enthalpy, $h$, specific entropy, $s$, and the other thermodynamic properties are calculated from the integrals and derivatives of the derived polynomials, $\rho(T)-c_{p}(T)$. As the presented dynamic models can be used for both compressible and incompressible fluids, pressure, $p$, and specific enthalpy, $h$, are selected as state variables. The Modelica table based media model uses an internal solver to retrieve the temperature value in order to compute the other thermodynamic properties. In figure 2 the developed dynamic model of the oil loop (loop I) of the system is shown. This work focuses on investigating the effectiveness of the control logic in the oil loop which is considered the most critical aspect of the system. Perfect ideal control is assumed in the water loop (loop II). The building thermal demand (TL) is modeled by means of a source of mass flow fed to the HXI secondary side. In the following sub-sections, the dynamic models of the system components are briefly described.

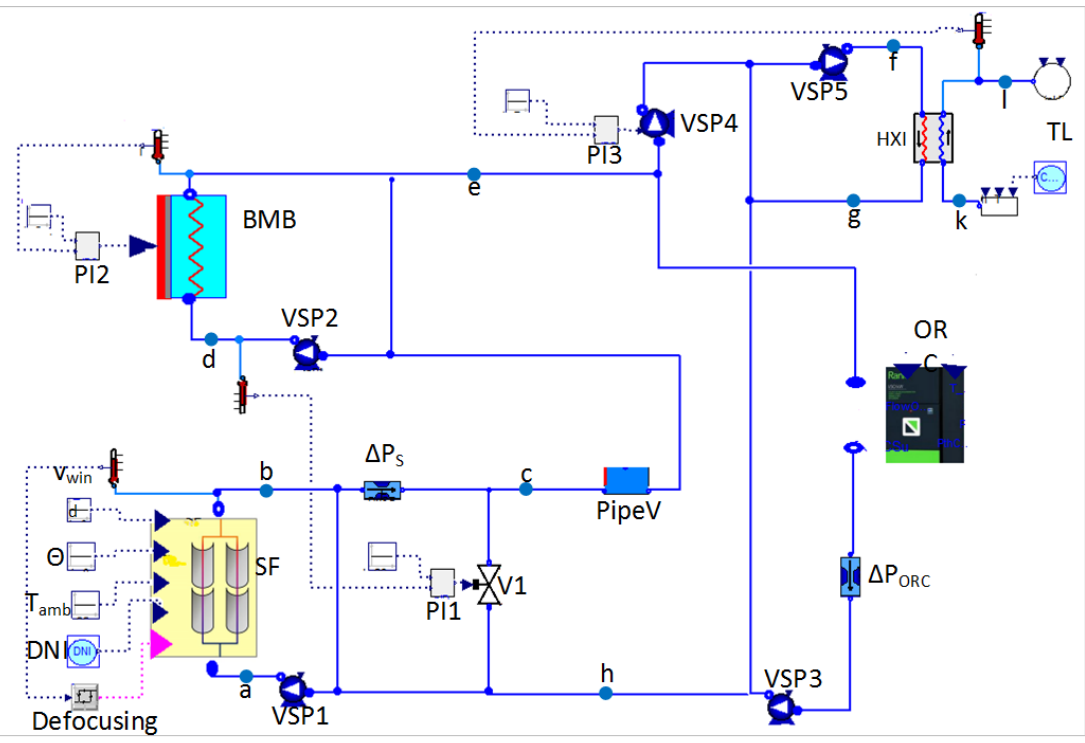

Fig. 2 Modelica model of the system from the Modelica/Dymola GUI. 


\subsection{Solar field}

Assuming homogeneous pressure drop and equal ambient input data, the solar field can be modeled as a single row of 3 collectors in series with a forth (1/4) of the total mass flow flowing through it. The parabolic through collector model of the ThermoCycle library is used. Given the large ratio between the diameter and the length of the parabolic through unit, the modeling approach is based on a finite volume one-dimensional discretization along the collector axial axis. The model is composed by two subcomponents. The Flow IDim component models the fluid flow through the heat collector element (HCE) accounting for energy and mass accumulation. The thermal inertia in the HCE is accounted by a the MetalWall model. The radial energy balance between the HCE and the ambient is modeled with a semi-empirical correlation derived from typical values of solar collectors of comparable size. This approach allows reducing the number of equations increasing the computational time, while still modeling the main time constant characterizing the solar field dynamics.

\subsection{Biomass boiler}

No information where provided by the manufacturer on the biomass burning process. As a consequence a simplified approach is adopted to simulate the boiler. The biomass burning process is modeled as a zerodimensional model where the power from the biomass combustion is imposed by the user, defining a value between 0 , shut-down, and 1, maximum power. A first order model allows to account for the combustion dynamic with a fixed time constant. The oil side and the tube metal walls are modeled with a discretized onedimensional approach. The oil flow through the boiler is modeled with a FlowlDim component, accounting for energy accumulation, while the thermal energy capacity of the metal walls is modeled using the MetalWall component. The thermal inertia of the boiler is tuned in order to reproduce typical values that are found on boiler of the same size $\left(500 \mathrm{~kW}_{\mathrm{el}}\right)$. The dynamic is check by simulating the warm up of the boiler, and verifying that the period of time required to reach the desired set point in temperature is close to realistic values ( 1 to 2 hours).

\subsection{Oil-Water heat exchanger}

The oil-water heat exchanger is modeled using the HxIDInc model of the ThermoCycle library. It models a counter-current plate heat exchanger based on the connection of three discretized one-dimensional subcomponents. Two FlowlDim components accounting for mass and energy accumulation of the fluids flowing on the two sides of the exchanger, and one MetalWall component accounting for energy accumulation in the metal plates. The model are discretized based on the finite volume approach with an upwind scheme. No pressure losses are considered in the two Flow1Dim models. Equation 1 is used to model the convective fluid-wall heat transfer coefficient to account for mass flow variation:

$$
\mathrm{U}=\mathrm{U}_{\text {nom }}\left(\frac{\dot{\mathrm{m}}}{\dot{\mathrm{m}}_{\text {nom }}}\right)^{\mathrm{n}}
$$

where the exponent $\mathrm{n}$ varies depending on the flow regime between 0.65 and 0.8 .

\subsection{ORC power unit}

In a small capacity ORC unit, the dynamic is mainly defined by energy and mass transfer phenomena characterizing the heat exchanger components, as the expansion and compression processes are characterized by very small time constants. A semi-empirical curve is derived based on experimental data to predict the electrical output power as a function of the heat source temperature at the evaporator inlet and the heat sink temperature at condenser inlet. In order to account for the dynamics characterizing the evaporation process a model equivalent to the one used for the oil-water heat exchanger is selected.

\subsection{Piping}

In order to account for the volume of the piping system between the solar field and the biomass boiler, the PipeV component is used. The model is a lumped one dimensional model accounting for mass accumulation in liquid phase in a defined constant volume. A constant pressure is imposed by the model, allowing for a robust resolution of the system of equation of the overall plant model. 


\subsection{Pump, pressure drop, bypass valve and PID}

The Pump model from the ThermoCycle library is used to simulate the pump units installed on the system. It is a lumped fictitious model simulating the compression of a fluid in a turbo or volumetric machine, where given the flow fraction or the pump frequency, a constant volumetric and isentropic efficiency, the mass flow and the consumed power are computed. No dynamics are considered as the time constant characterizing the compression processes are very small compared to the ones regulating heat transfer phenomena. Pressure drop through the solar field and the ORC evaporator heat exchanger are modeled with the lumped $\triangle P$ model of the ThermoCycle library. The model computes a punctual pressure drop assuming fluid incompressibility and no thermal energy losses to the ambient. A linear and quadratic pressure drop terms are used to compute the total pressure drop. The homotopy function (Casella et al., 2011) is used during initialization to set the pressure drop to zero, facilitating the convergence of the solver. Finally the expansion of the fluid through the by-pass valve of the solar field system is modeled with the Valve model from the ThermoCycle library. The model is a lamped model where no dynamic and thermal energy losses to the ambient are considered. Finally the PID described in section 3 are implemented in modelica using the PID model of the ThermoCycle library.

\section{Results and discussion}

The dynamic model of the complete system described in section 4 and controlled according to the control logic described in section 3 is simulated under transient conditions. The main goal of this study is to investigate if the whole system can be safely and efficiently operated with the proposed automated control logic. From the safety point of view, the main concern is related to the biomass boiler, the ORC system and the adsorption chiller, which need to be operated respecting the technical boundaries described in section 3 . From the efficiency point of view, maximum exploitation of the solar resources should be ensured in order to minimize the biomass combustion rate. At the same time keeping the oil temperature at the ORC evaporator inlet $\left(\mathrm{T}_{\mathrm{e}}\right)$ and the water temperature to the adsorption machine $\left(\mathrm{T}_{1}\right)$ close to their nominal values, allows for on-design working conditions maximizing the overall system efficiency. The dynamic model of the whole plant is simulated under a transient condition representative of an extreme reference situation characterized by a periodically sharp drop of the solar input due to the passage of a series of clouds (Casati et al., 2012). The thermal load at the oil-water heat exchanger is assumed constant over the simulation time imposing a constant mass flow rate on the secondary side of the HXI component. The results are shown in figure 3.

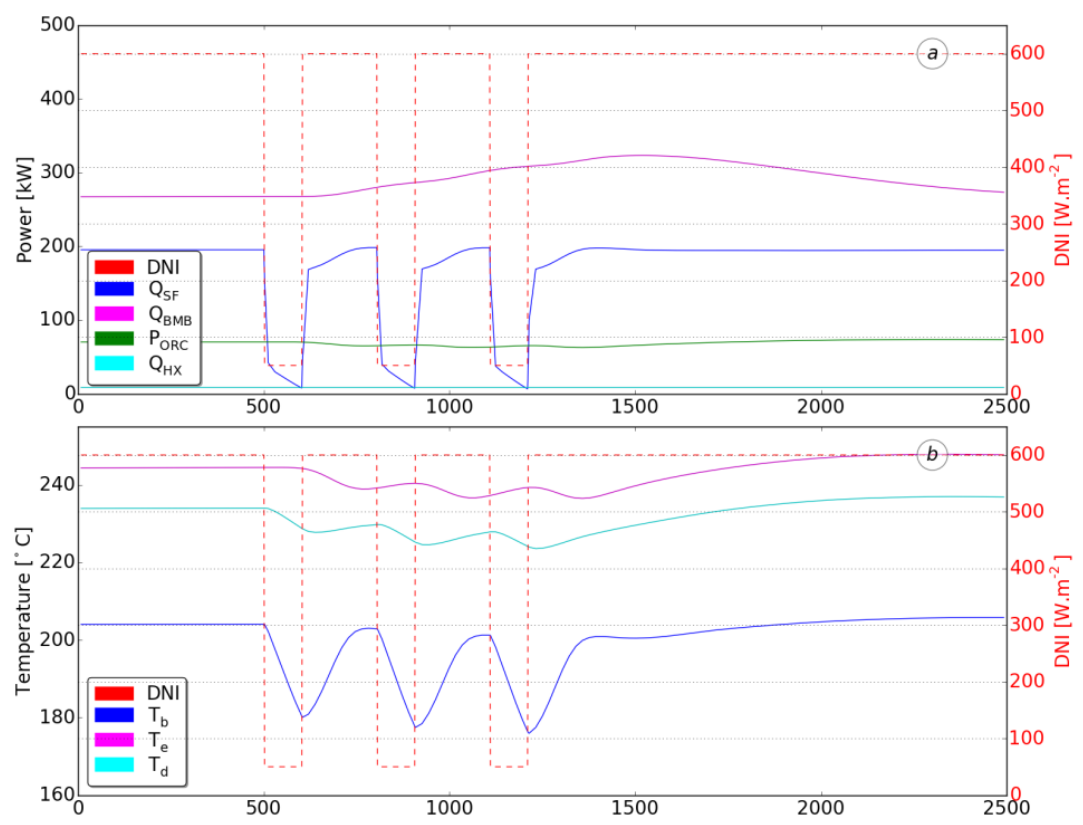

Fig. 3: Dynamic simulation results of the whole plant model as shown in figure 2. The red dotted represents the DNI: it drops by $100 \%$ of its nominal value in $2 \mathrm{~s}$, remain constant for $200 \mathrm{~s}$ then returns to its nominal value in $2 \mathrm{~s}$. the interval between two subsequent drop is $200 \mathrm{~s}$. (a) Thermal power delivered by the solar field, the biomass, the ORC evaporator and the HX oil/water evaporator (b) Temperature values in key points of the system. 
The solar input drop is modeled by applying a signal with three subsequent ramps to the DNI input of the solar field model. The DNI drops by $90 \%$ of its nominal value, perturbing the initial steady state condition. From the results, it appears that the time constants characterizing the biomass system are large enough to cause an overlapping effect of the disturbances. The variation of the controlled biomass thermal power, $Q_{\mathrm{BMB}}$, is shown in figure 3a. Despite the sharp drop of the power absorbed in the solar field, $Q_{S F}$, the ORC electrical power, $P_{\text {orc }}$, is maintained close to its nominal value with a maximum deviation of $10 \%$. The temperatures variation are reported in figure $3 \mathrm{~b}$. The significant oscillations of the temperature at solar field outlet, $\mathrm{T}_{\mathrm{b}}$, are dumped by the biomass boiler recirculation system and the temperature at the boiler inlet, $\mathrm{T}_{\mathrm{d}}$, results characterized by much lower variations maintaining the biomass boiler temperature gradient between 9 and $15 \mathrm{~K}$. The results show that through a mild regulation of the biomass boiler the system is able to run the ORC unit close to its nominal working condition despite the sharp drop of sun power. The effectiveness of the biomass system in decoupling the solar field from the ORC unit is assessed. In order to investigate and compare the performance of partial and total defocusing control logic implemented on the solar field, the dynamic model is simulated during a reference summer day in Caceres, Spain. The high value of the DNI is expected to trigger the defocusing mechanism. Two different simulations are run, one considering a constant negligible building thermal demand and one considering a variable thermal load based on available empirical data. In figure 4 the simulation results for a partial (PD) and a total (TD) solar field defocusing are compared when a constant low building thermal demand is assumed. The simulation starts at 5:00 am and last for 17 hours. During the night the DNI is zero and the biomass is running close to its maximum power to provide the thermal energy required by the ORC power block. When the sun rises, at around 6:00 am, the thermal power provided by the solar field, $Q_{S F}$, starts increasing and the biomass power, $Q_{B M B}$, is consequently decreased by the control as the thermal power demand stays constant as shown in figure 4a. Looking at figure $4 \mathrm{~b}$, the increase of $T_{b}$ causes the temperature at biomass inlet, $T_{d}$, to rise. As a consequence PI1 starts opening V1 to bypass the solar field and keep $T_{d}$ close to its nominal point. The mass flow through the solar field by-pass valve and the solar field recirculation circuit increases proportionally as shown in figure 4c. This mechanism boosts $T_{b}$ towards its upper limit value, pushing the solar field into the defocusing mode and avoiding the shut-down of the biomass boiler. As the defocusing mode is activated, the system behavior changes significantly depending on the adopted defocusing approach. In the PD case, solid lines, one forth of the solar field is defocused. The partial decrease in the solar collector effective surface allows for a smooth decrease of the solar field outlet temperature, $T_{b}$, bringing the system in a second steady working condition. In the TD case, dashed lines, the total defocusing of the solar collector causes a sharp decrease of the evaporator outlet temperature down to its minimum value which consequently triggers the solar field to exit the defocusing mode. As the DNI is roughly constant during the simulated reference day, the focusingdefocusing control runs continuously. A continuous control of the biomass system to overcome the sharp changes of the solar field thermal power is deemed necessary. As a consequence the overall system is characterized by an oscillatory trend. When the sun starts to set between 17:00 and 18:00, $\mathrm{T}_{\mathrm{b}}$ reaches its lowest value that triggers the solar field to exit the defocusing mode. The drop of solar energy at the end of the day is compensated by the biomass power which is increased to meet the required thermal power demand. 


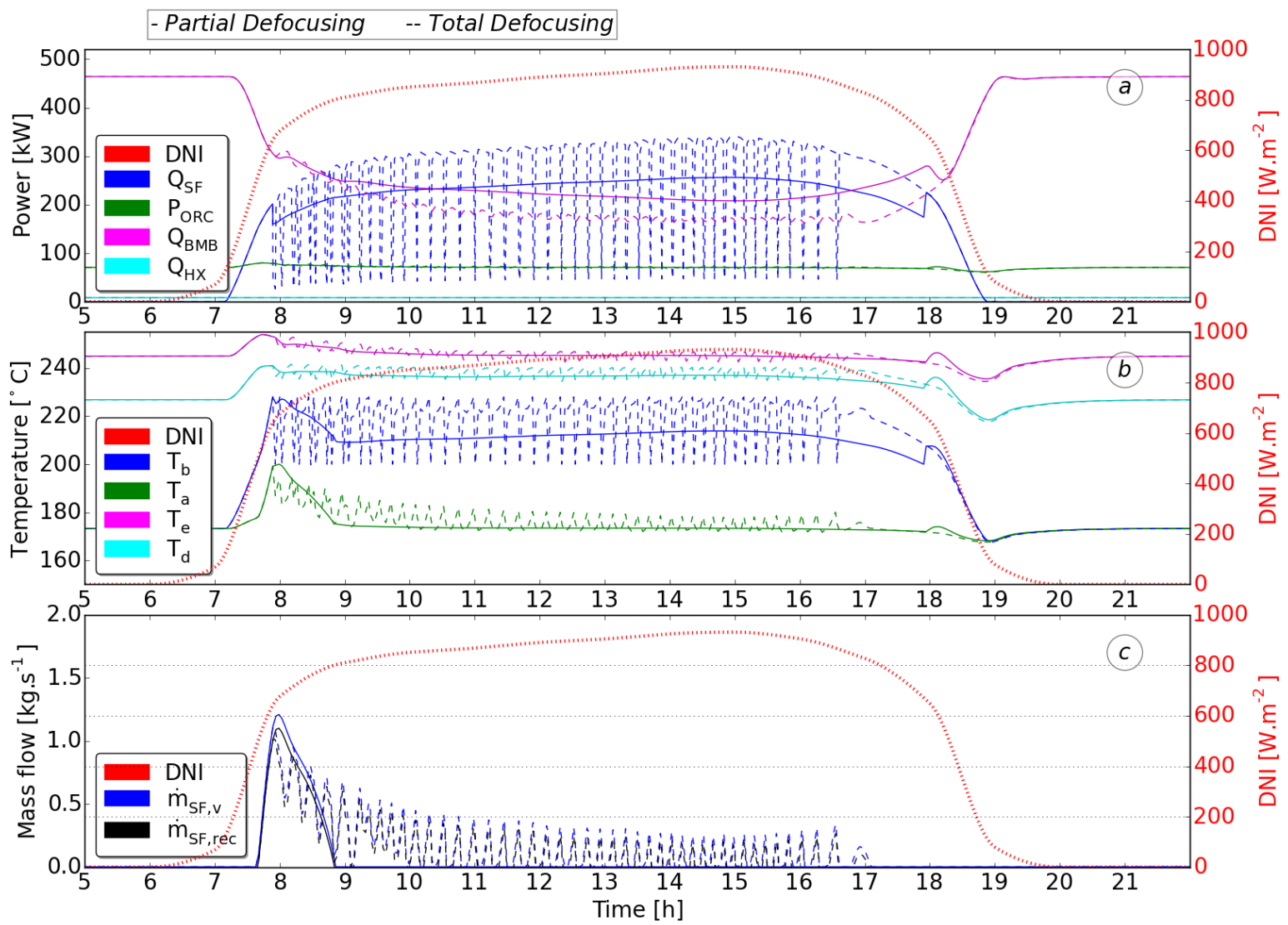

Fig. 4 Dynamic simulation results of the whole plant model during a reference summer day in Cacares, Spain. The dashed line represents the results for a solar field control strategy based on a total defocusing, the solid line for a partial defocusing. (a) Thermal power delivered by the solar field, the biomass, the ORC evaporator and the HX oil/water evaporator (b) Temperature values in key points of the system (c) Mass flows of the solar field bypass and recirculation system.

Overall both defocusing methods are able to maintain the system in safe working conditions during the simulated reference day. The temperature gradient at the biomass boiler is kept between 18 and $8 \mathrm{~K}$. The ORC power block is run continuously with a maximum power deviation of $12.6 \%$ and $14 \%$ in the PD and the TD case respectively. At the cost of a continuous regulation of the solar field inclination, the TD approach allows a reduction of the total thermal energy delivered by the biomass boiler of $8 \%$ with respect to the PD mode consuming a smaller amount of biomass. Defining the solar fraction, $\mathrm{E}_{\mathrm{SF}, \mathrm{r}}$ as:

$\mathrm{E}_{\mathrm{SF}, \mathrm{r}}=\frac{E_{S F}}{E_{B M}}=\frac{\int \dot{Q}_{S F} d t}{\int \dot{Q}_{B M} d t}$

where $\mathrm{E}_{\mathrm{SF}}$ is the total energy delivered by the solar field and $\mathrm{E}_{\mathrm{BM}}$ is the total energy delivered by the biomass over a period of $17 \mathrm{~h}$ from 5:00 to 22:00. The TD approach results in a solar fraction of 59\% while the PD in a solar fraction of $47 \%$. The simulation results for the same reference day considering a variable thermal load demand are reported in figure 5. As in the previous simulation, the DNI increase triggers the defocusing mechanism around 8:00 am. The PD approach brings the system to a steady condition while the TD approach causes an oscillatory behavior in the system. As shown in figure 5a, around 9:00 am the building thermal demand start increasing and more power is required by $\mathrm{HX} 1, \mathrm{Q}_{\mathrm{HX}}$. As more thermal energy is required, the solar field inlet temperature $T_{a}$ decreases and so does $T_{b}$ reaching its lowest value which causes the solar field to exit its defocusing mode around 9:30 am. From this time on the TD and PD approaches lead to the same results. As the thermal demand keeps increasing during the day, the biomass boiler power is regulated to meet the thermal needs. From a safety point of view the control logic is able to maintain the biomass boiler temperature gradient between the required limit with a minimum of $9 \mathrm{~K}$ and a maximum of $20 \mathrm{~K}$. The ORC power block inlet temperature experience the biggest drop around 19:00 and 21:00 when the sun goes 
down and the biomass is brought close to its maximum value to provide the requested thermal power. The ORC evaporator inlet temperature smoothly decrease reaching a minimum value of $233^{\circ} \mathrm{C}$ which corresponds to an electrical power drop of $17 \%$ with respect to the nominal power. Overall the TD case allows a reduction of the biomass boiler of only $0.5 \%$ with respect to the PD case as the two approaches leads to the same plant trend for most of the time. As a consequence a solar fraction of 53\% and $54 \%$ is found for the PD and the TD case respectively.

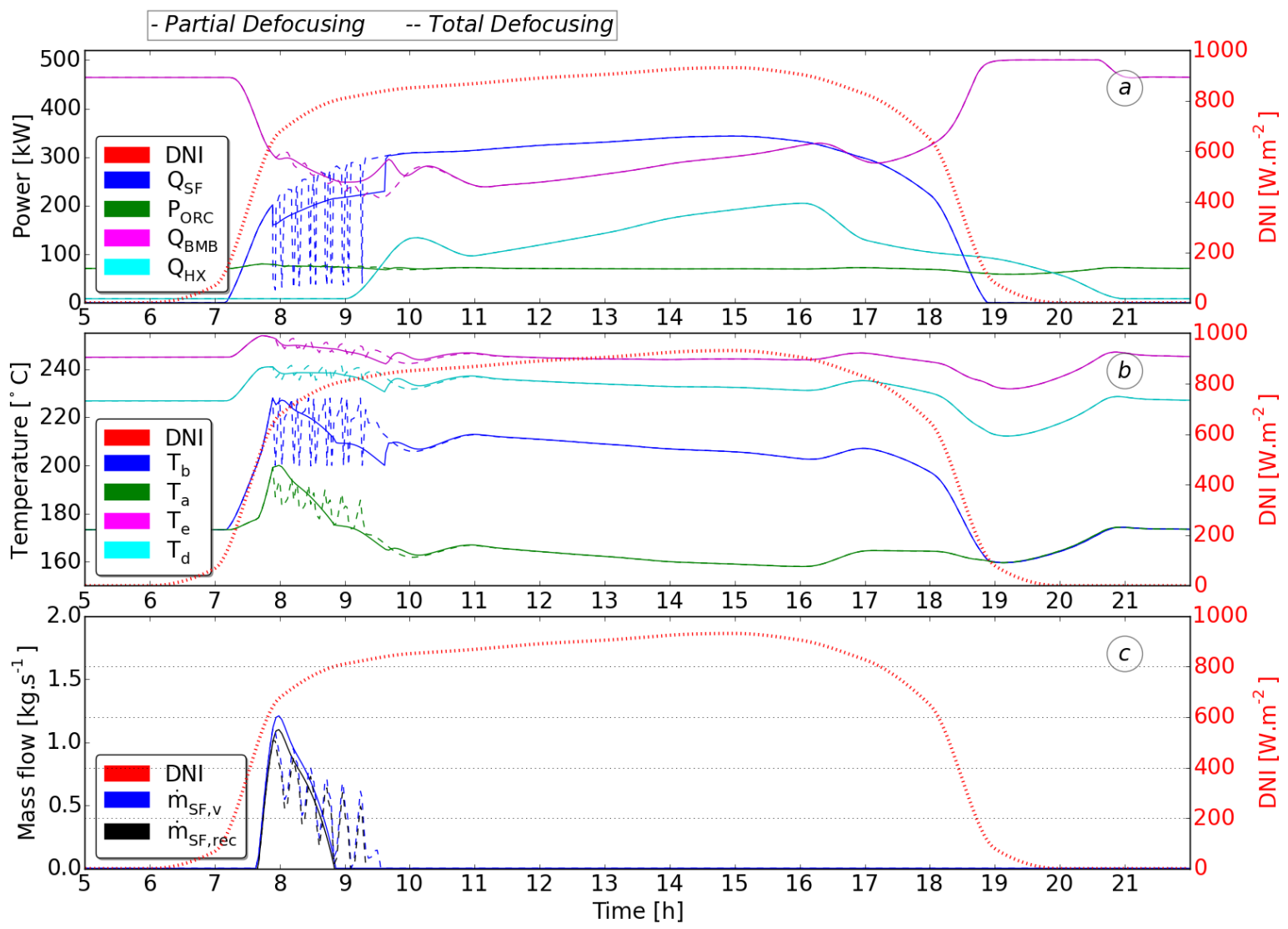

Fig. 5 Dynamic simulation results of the whole plant model during a reference summer day in Cacares, Spain with variable required thermal power. The dashed line represents thre results for a solar field control strategy based on a total defocusing (TD), the solid line for a partial defocusing (PD). (a) Thermal power delivered by the solar field, the biomass, the ORC evaporator and the HX oil/water evaporator (b) Temperature values in key points of the system (c) Mass flows of the solar field bypass and recirculation system.

\section{Conclusions and future work}

In this work the CSP-biomass CHP system based on ORC technology developed in the framework of the EU founded BRICKER project is presented. The system has the goal of meeting the building energy demand with the employment of only renewable energy sources. A detailed description of the different system component is reported. Given the technical boundaries of the different component, a control logic is developed to maintain safe operating condition during different working conditions. In order to test the implemented control logic a dynamic model of the whole system is developed. The dynamic model is based on the Modelica programming language and the components models are developed based on the ThermoCycle library adopting a simple modeling approach. The reaction to the passage of sub- sequent clouds, causing the solar input to drop to $90 \%$ of its nominal value, is simulated to test the control capability to ensure safe condition. The effectiveness of the biomass boiler to decouple the solar field to the HXI and ORC units is assessed. The system is able to withstand fast variation of the sun power as demonstrated by the results of the first simulation reported in figure 3. Variation in solar field outlet temperature of $30 \mathrm{~K}$ results in variation at the evaporator ORC inlet temperature of $8 \mathrm{~K}$ causing a decrease in electrical power of $8 \%$ with respect to its nominal power. Furthermore, two solar field defocusing approach are investigated in two 
different conditions, one with constant thermal power and one with variable thermal power. In both situations the two approaches allows to operate the system within the safety limits imposed by the ORC unit and the biomass boiler. The effectiveness of the two approaches in exploiting the sun power is assessed in terms of the solar fraction. The TD approach allows to increase the solar fraction of up to 12 percentage point compared to the PD case at the cost of continuously running the electric motor of the solar field. In the next phase of the project, the developed dynamic model will be integrated with the model of the adsorption chiller and of the reference building to investigate in detail the control strategy that allows to maximize the solar fraction while maintaining safe working conditions.

\section{Acknowledgement}

The result presented in this paper is part of the BRICKER project (www.bricker-project.com). This project has received funding from the European Union's Seventh Framework Programme for research, technological development and demonstration under grant agreement No 609071. The information reflects only the author's view and the Commission is not responsible for any use that may be made of the information it contains.

\section{References}

IEA, 2014. Technology Roadmap Solar Thermal Electricity - 2014 edition.

Alberti, F., Crema, L., Bozzoli, A., 2012. Heat Transfer Analysis for a Small-Size Direct-Flow Coaxial Concentrating Collector. J. Sol. Energy Eng. 134, 041009. doi:10.1115/1.4007297

Angelino, G., Gaia, M., Macchi, E., 1984. Review of Italian Activity in the Field of Organic Rankine Cycles. VDI Berichte.

Cabello, J.M., Cejudo, J.M., Luque, M., Ruiz, F., Deb, K., Tewari, R., 2011. Optimization of the size of a solar thermal electricity plant by means of genetic algorithms. Renew. Energy 36, 3146-3153. doi:10.1016/j.renene.2011.03.018

Casati, E., Desideri, A., Casella, F., Colonna, P., 2012. Preliminary Assessment of a Novel Small CSP Plant Based on Linear Collectors, ORC and Direct Thermal Storage. SolarPaces Conf.

Casella, F., Sielemann, M., Savoldelli, L., 2011. Steady-state initialization of object-oriented thermo-fluid models by homotopy methods. 8th Model. Conf. 86-96.

Dickes, R., Desideri, A., Lemort, V., Quoilin, S., 2015. Model reduction for simulating the dynamic behavior of parabolic troughs and a thermocline energy storage in a micro-solar power unit.

Elmqvist, H., Mattsson, S.E., 1997. Modelica — the Next Generation Modeling Language an International Design Effort. Proc. 1st World Congr. Syst. Simul. 1-5. doi:10.1.1.16.3600

Hinkley, J., Curtin, B., Hayward, J., IWonhas, A., Boyd, R., Grima, C., Tadros, A., Hall, R., Naicker, K., Mikhail, A., 2011. Concentrating solar power - drivers and opportunities for cost-competitive electricity $1-32$.

Ireland, M., Orsoz, M., Desideri, A., Quoilin, S., DesuBrisson, J.G., 2014. Dynamic modeling and control system definition for a micro-CSP plant coupled with thermal storage unit, in: Proceedings of ASME Turbo Expo 2014: Turbine Technical Conference and Exposition.

Mattson, S.E., Elmqvist, H., Broenink, J.F., 1997. Modelica: An international effort to design the next generation modelling language. J. A 38, 16-19. 
Mediavilla, M., de Castro, C., Capellán, I., Javier Miguel, L., Arto, I., Frechoso, F., 2013. The transition towards renewable energies: Physical limits and temporal conditions. Energy Policy 52, 297-311. doi:10.1016/j.enpol.2012.09.033

Palm, B., Claesson, J., 2006. Plate Heat Exchangers: Calculation Methods for Singleand Two-Phase Flow. Heat Transf. Eng. 27, 88-98. doi:10.1080/01457630500523949

Peterseim, J.H., Hellwig, U., Tadros, A., White, S., 2014a. Hybridisation optimization of concentrating solar thermal and biomass power generation facilities. Sol. Energy 99, 203-214. doi:10.1016/j.solener.2013.10.041

Peterseim, J.H., Tadros, A., Hellwig, U., White, S., 2014b. Increasing the efficiency of parabolic trough plants using thermal oil through external superheating with biomass. Energy Convers. Manag. 77, 784793. doi:10.1016/j.enconman.2013.10.022

Peterseim, J.H., White, S., Tadros, A., Hellwig, U., 2013. Concentrated solar power hybrid plants, which technologies are best suited for hybridisation? Renew. Energy 57, 520-532.

doi:10.1016/j.renene.2013.02.014

Pitz-Paal, R., Dersch, J., Milow, B., Téllez, F., Ferriere, A., Langnickel, U., Steinfeld, A., Karni, J., Zarza, E., Popel, O., 2007. Development Steps for Parabolic Trough Solar Power Technologies With Maximum Impact on Cost Reduction. J. Sol. Energy Eng. 129, 371. doi:10.1115/1.2769697

Quoilin, S., Broek, M. Van Den, Declaye, S., Dewallef, P., Lemort, V., 2013. Techno-economic survey of organic rankine cycle (ORC) systems. Renew. Sustain. Energy Rev. 22, 168-186. doi:10.1016/j.rser.2013.01.028

Quoilin, S., Desideri, A., Wronski, J., Bell, I., Lemort, V., 2014. ThermoCycle: A Modelica library for the simulation of thermodynamic systems 683-692. doi:10.3384/ecp14096683

Resnick Institute, 2012. Grid 2020 Towards a Policy of Renewable and Distributed Energy Resources.

Soria, R., Portugal-Pereira, J., Szklo, A., Milani, R., Schaeffer, R., 2015. Hybrid concentrated solar power (CSP)-biomass plants in a semiarid region: A strategy for CSP deployment in Brazil. Energy Policy 86, 57-72. doi:10.1016/j.enpol.2015.06.028

Sterrer, R., Schidler, S., Schwandt, O., Franz, P., Hammerschmid, A., 2014. Theoretical Analysis of the Combination of CSP with a Biomass CHP-plant Using ORC-technology in Central Europe. Energy Procedia 49, 1218-1227. doi:10.1016/j.egypro.2014.03.131

Wang, B.K., Vineyard, E. a, 2011. Adsorption Refrigeration. Ashrae. 